\title{
Is it really dumb to leave a stump?
}

Konrad Hoetzenecker, MD, PhD, and Walter Klepetko, MD

From the Division of Thoracic Surgery, Medical University of Vienna, Vienna, Austria

Disclosures: Authors have nothing to disclose with regard to commercial support.

Received for publication Nov 11, 2017; accepted for publication Nov 15, 2017; available ahead of print Jan 2, 2018.

Address for reprints: Konrad Hoetzenecker, MD, PhD, Division of Thoracic Surgery, Medical University of

Vienna, Waehringer Guertel 18-20, 1090 Vienna, Austria (E-mail: konrad.hoetzenecker@meduniwien.ac.at). J Thorac Cardiovasc Surg 2018;156:461-2

$0022-5223 / \$ 36.00$

Copyright (C) 2017 by The American Association for Thoracic Surgery

https://doi.org/10.1016/j.jtcvs.2017.11.064

In this issue of the Journal, Kayawake and colleagues ${ }^{1}$ report on the outcomes of bronchial stumps left during lobar lung transplantation.

The authors retrospectively analyzed their institutional experience of living-donor, lobar-lung, and down-sized cadaveric-donor lung transplantations. In an unparalleled large series of 145 lobar transplantations, they identified 22 patients who received lobar-to-lobar bronchial anastomosis. In 21 of those patients, there was an additional remaining bronchial stump. No complications related to the lobar-to-lobar anastomoses were found, and all bronchial stumps healed well.

Since the beginning of lung transplantation, the lack of antegrade bronchial circulation has been identified as an important driver of bronchial complications. Bronchial blood supply of the donor is completely dependent on retrograde collaterals from the pulmonary circulation after transplantation. ${ }^{2,3}$ On the other hand, bronchial blood supply on the recipient side is usually not impaired, especially because the operative technique clearly differs from oncologic operations, where a maximum of lymphatic tissue is removed. Thus, the healing potential of a bronchial stump on the recipient side should be even

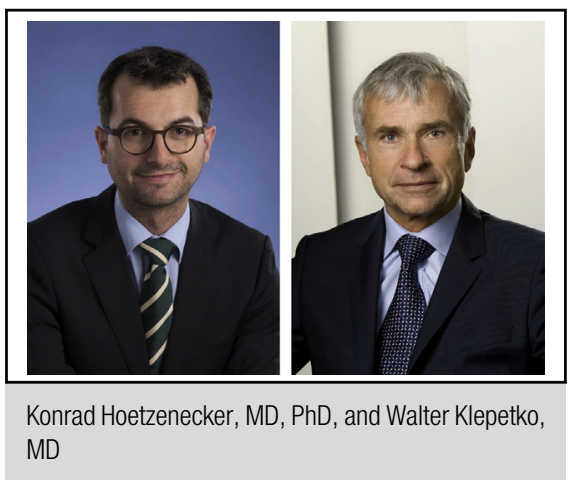

\section{Central Message}

Leaving a bronchial stump on the donor side is a safe strategy in lobar transplantation with excellent primary healing and no long-term complications.

See Article page 451 .

better than after oncologic resections. Indeed, the current article supports these considerations by reporting adequate healing of all recipient stumps. These results are also well in line with the limited experience with split lung transplantation, where a right upper lobe stump in the recipient always remains. ${ }^{4,5}$

Although Kayawake and colleagues ${ }^{1}$ have to be commended on their outstanding results, the concept of lobar-to-lobar anastomosis with a subsequent bronchial stump requires a closer look (Figure 1, $A$ ). In standard lobar transplantation, surgeons in most centers would perform the

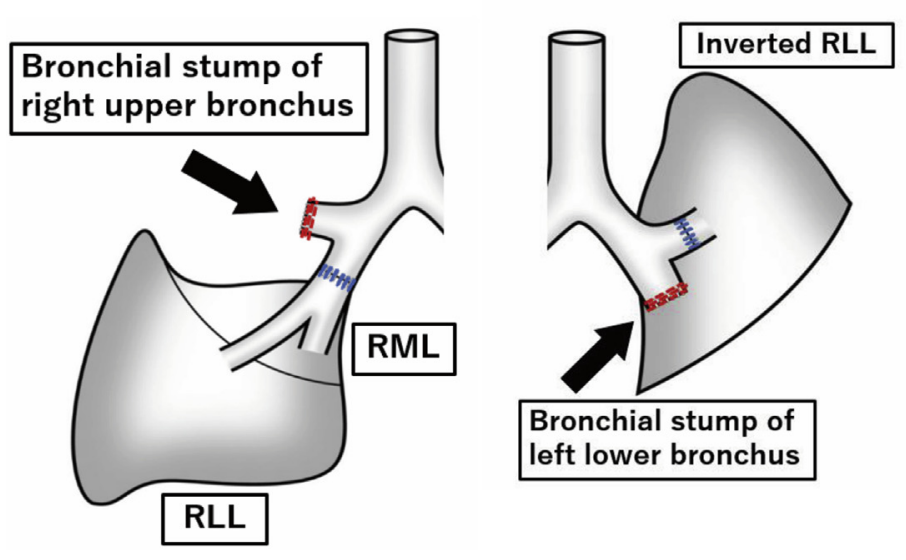

A

B

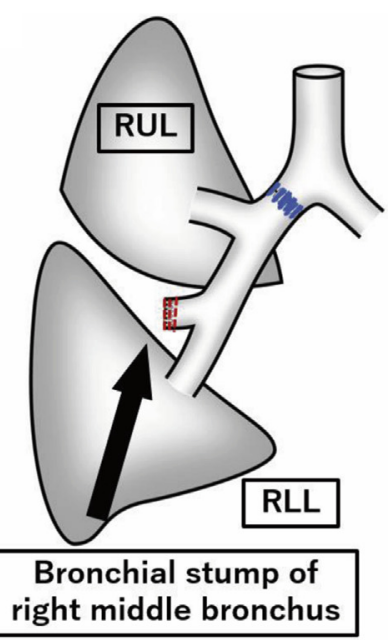

FIGURE 1. Two examples of recipient bronchial stumps in lobar transplantation (A). Anatomic middle lobectomy for size reduction in cadaveric lung recipients (B). $R L L$, Right lower lobe; $R M L$, right middle lobe; $R U L$, right upper lobe. 
anastomosis between the recipient's main bronchus and the respective lobar bronchus of the donor. In experienced hands, this is a safe technique with excellent long-term results. ${ }^{6}$ Size discrepancy usually can be managed by careful placement of the stitches. ${ }^{7}$ In the majority of cases, telescoping, generally considered a risk factor for anastomotic sequelae, can be avoided. ${ }^{8,9}$

However, different considerations apply for stumps remaining on the donor side because of the mentioned retrograde bronchial perfusion after transplantation. A total of 3 of 8 reported cadaveric lung recipients received an anatomic middle lobe lobectomy to downsize the graft (Figure 1, B). Such an operative strategy creates the potential to impair the retrograde perfusion of the main bronchus and requires a meticulous operative technique. In fact, an easier alternative to achieve down-sizing is available through simple extra-anatomic stapler resection of the middle lobe, which has been widely used with extremely low complication rates. ${ }^{10}$ Most parts of the middle lobe, or alternatively the lingula on the left side, can be removed in this way, resulting in up to $20 \%$ reduction of total lung capacity. ${ }^{11}$ In view of such a safe and simple alternative, the true value of anatomic middle lobe resection needs to be confirmed in a larger group of patients.

Although, in general, bronchial stumps should be avoided in lung transplantation, it is not completely dumb to leave a stump under specific circumstances.

\section{References}

1. Kayawake H, Chen-Yoshikawa TF, Aoyama A, Motoyama H, Hamaji M, Hijiya K. Surgical management of bronchial stumps in lobar lung transplantation. J Thorac Cardiovasc Surg. 2018;156:451-60.

2. Siegelman SS, Hagstrom JW, Koerner SK, Veith FJ. Restoration of bronchial artery circulation after canine lung allotransplantation. J Thorac Cardiovasc Surg. 1977;73:792-5.

3. Pearson FG, Goldberg M, Stone RM, Colapinto RF. Bronchial arterial circulation restored after reimplantation of canine lung. Can J Surg. 1970;13: 243-50.

4. Couetil JP, Tolan MJ, Loulmet DF, Guinvarch A, Chevalier PG, Achkar A, et al. Pulmonary bipartitioning and lobar transplantation: a new approach to donor organ shortage. J Thorac Cardiovasc Surg. 1997;113:529-37.

5. Artemiou O, Birsan T, Taghavi S, Eichler I, Wisser W, Wolner E, et al. Bilateral lobar transplantation with the split lung technique. J Thorac Cardiovasc Surg. 1999;118:369-70.

6. Inci I, Schuurmans MM, Kestenholz P, Schneiter D, Hillinger S, Opitz I, et al. Long-term outcomes of bilateral lobar lung transplantation. Eur J Cardiothorac Surg. 2013;43:1220-5.

7. Slama A, Ghanim B, Klikovits T, Scheed A, Hoda MA, Hoetzenecker K, et al. Lobar lung transplantation-is it comparable with standard lung transplantation? Transpl Int. 2014;27:909-16.

8. Van De Wauwer C, Van Raemdonck D, Verleden GM, Dupont L, De Leyn P, Coosemans W, et al. Risk factors for airway complications within the first year after lung transplantation. Eur J Cardiothorac Surg. 2007;31: $703-10$.

9. Garfein ES, Ginsberg ME, Gorenstein L, McGregor CC, Schulman LL. Superiority of end-to-end versus telescoped bronchial anastomosis in single lung transplantation for pulmonary emphysema. J Thorac Cardiovasc Surg. 2001;121:149-54.

10. Aigner C, Winkler G, Jaksch P, Ankersmit J, Marta G, Taghavi S, et al. Size-reduced lung transplantation: an advanced operative strategy to alleviate donor organ shortage. Transplant Proc. 2004;36:2801-5.

11. Aigner C, Jaksch P, Taghavi S, Wisser W, Marta G, Winkler G, et al. Donor total lung capacity predicts recipient total lung capacity after size-reduced lung transplantation. J Heart Lung Transplant. 2005;24:2098-102. 